\title{
AN EXPERIMENTAL STUDY OF THE MOTION OF ICE PAST OBSTACLES BY THE PROCESS OF REGELATION
}

\author{
By E. M. MORRIS*
}

\author{
(H. H. Wills Physics Laboratory, University of Bristol, Bristol BS8 ITL, England)
}

\begin{abstract}
The results of regelation experiments, in which a single object is pulled through ice, cannot be applied directly to the problem of basal sliding in glaciers because the two systems have different geometries. When the force applied to a single object is small, impurities trapped in the regelation water-layer around the object inhibit the regelation process. At larger forces, above the Drake-Shreve transition point, impurities are shed in a trace behind the object. However, when ice moves over a series of obstacles a trace may exist above and below the transition point. The regelation velocity below the transition point is not reduced by the effect of trapped impurities. In an experiment in which brass cylinders of various cross-sections rotate in ice, the ratio between the expected regelation velocity, calculated using the basal-sliding theory of Nye, and the measured regelation velocity is $8 \pm 2$, both above and below the transition point. The same ratio has been obtained by other workers with wires of similar thermal conductivity above the transition point. Measurements of temperature differences indicate that supercooling cannot be the main source of the unexpectedly low regelation velocities above the transition point.
\end{abstract}

RÉsumÉ. Expériences sur le mouvement de la glace franchissant des obstacles par regel. Les résultats d'expériences de regel dans lesquelles un objet isolé est poussé à travers la glace ne peuvent s'appliquer directement au problème du glissement à la base des glaciers sur leur lit, parce que les deux systèmes ont des géométries différentes. Lorsque la force appliquée à un objet isolé est petite, les impuretés emprisonnées dans le niveau d'eau de regel empêchent autour d'elles le processus de regel. Pour des forces supérieures au-dessus du point de transition de Drake-Shreve, les impuretés se concentrent dans un sillage derrière l'objet. Quoiqu'il en soit, lorsque la glace se déplace au-dessus d'une série d'obstacles, un sillage peut se produire au-dessus et en-dessous du point de transition. La vitesse de regel en-dessous du point de transition n'est pas réduite par l'effet des impuretés emprisonnées. Dans une expérience où des cylindres de laiton de section variable tournent dans la glace, le rapport entre les vitesses de regel attendues en appliquant la théorie du glissement sur le lit glaciaire de Nye, et la vitesse de regel mesurée est de $8 \pm 2$, au-dessus et en-dessous du point de transition. Le même rapport a été obtenu par des autres travailleurs avec des fils métalliques de conductivité thermique similaire au-dessus du point de transition. Les mesures de différences de températures montrent que le surfusion ne peut pas être la source principale de vitesses de regel plus basses qu'attendues au-dessus du point de transition.

Zusammenfassung. Versuche zur Regelationsbewegung von Eis um Hindernisse. Die Ergebnisse von Regelationsversuchen, bei denen Einzelobjekte durch Eis gezogen werden, können nicht unmittelbar auf das Problem des Gleitens am Untergrund von Gletschern angewandt werden, da Unterschiede in der Geometrie der beiden Systeme bestehen. Wenn die am Einzelobjekt angreifende Kraft klein ist, hemmen Verunreinigungen in der umgebenden Schmelzwasserschicht den Regelationsprozess. Bei grösseren Kräften, die über dem Drake-Shreve-Übergangspunkt liegen, sammeln sich die Verunreinigungen in einer Spur hinter dem Objekt. Wie auch immer, wenn Eis sich über eine Reihe von Hindernissen bewegt, kann eine Spur über oder unter dem Übergangspunkt vorhanden sein. Die Regelationsgeschwindigkeit unter dem Übergangspunkt wird durch die Wirkung der Verunreinigungen nicht verringert. In einem Versuch, bei dem MessingZylinder verschiedenen Querschnittes im Eis rotieren, ergab sich ein Verhältnis von $8 \pm 2$ zwischen der nach Nye's Gleittheorie zu erwartenden und der gemessenen Regelationsgeschwindigkeit, über und unter dem Übergangspunkt. Dasselbe Verhältnis wurde über dem Übergangspunkt mit Drähten von ähnlicher Wärmeleitfähigkeit erhalten. Messungen von Temperaturdifferenzen zeigen, dass Unterkühlung nicht die Hauptursache für die unerwartet niedrigen Regelationsgeschwindigkeiten über dem Übergangspunkt sein können.

\section{INTRODUCTION}

The basal sliding of a temperate glacier is controlled by a number of mechanisms; one of the most important of these is regelation. Ice moves past small obstacles on its bed by processes of melting and refreezing; these processes are essential if basal sliding is to occur (Weertman, 1957, 1964). However, the physics of this regelation process is still not clearly understood. The imperfections of the traditional regelation theory have been discussed theoretically by Frank ( 1967$)$ and Nye (1967, r973). Drake and Shreve (r973) have isolated several factors which may explain the marked differences between observed and expected results in laboratory experiments.

* Now at Institute of Hydrology, Crowmarsh Gifford, Wallingford, Oxfordshire, England. 
In one respect the nature of the regelation process in these experiments differs from the nature of regelation at the bottom of a glacier. On the one hand, single objects (wires or spheres for example) are pulled through virgin ice; on the other, the glacier flows over a series of obstacles and the lowest layer of ice melts and refreezes many times. Not all the processes which are thought to occur in traditional experiments may occur in precisely the same way during the basal sliding of temperate glaciers. Thus, a laboratory experiment in which ice moves by regelation over a series of obstacles is important as a link between the two geometries because it indicates how far the knowledge of regelation gained by traditional experiments may be applied to the problem of basal sliding.

\section{THEORY}

\section{(a) The motion of a single object through ice}

Figure I (a) shows a round wire moving at a steady velocity through a block of ice by regelation processes. The wire is surrounded by a layer of water. A constant force applied to the wire produces a stress distribution in the ice and water layer such that the highest water pressure is at point $P$ and the lowest is at point $Q$. The ice below the wire melts and the water produced by this melting flows to the low-pressure area above the wire where it refreezes with the release of latent heat. This heat flows back to the ice-water interface below the wire where melting continues.

The amount of melting or freezing required per unit time at each point on the ice-water interface can be calculated from the regelation velocity. Hence the distribution of latent heat sources and sinks on the inner boundary of the ice block is known. If melting and refreezing take place within the ice there will also be internal sources and sinks of heat. The temperature distribution in the ice block may be separated into two components: a known "regelation" temperature distribution, derived by considering the boundary sources and sinks only, and a second component which depends on the unknown distribution of internal sources and sinks. This point is discussed in more detail in section (c), (iii).

By definition, each point of the ice-water interface is at its melting point, the temperature of which is proportional to the component of stress normal to the interface. Thus, the temperature on the inner boundary may be expressed in terms of the applied force. However, the internal temperature distribution remains unknown because the melting point away from an interface is not defined unambiguously by the stress.

Nye (1967) has pointed out that an approximation must be made in order to solve the regelation equations. He suggested that, at the boundary, the contribution to the temperature distribution which arises from internal melting and refreezing may be neglected so that the temperature at the ice-water interface may be expressed in terms of the "regelation" temperature distribution. The temperature on the inner boundary is then known in terms of both the regelation velocity and the force on the wire. Hence the regelation velocity of the wire through the ice can be predicted from the applied force.

However, regelation velocities measured during experiments by Meerburg (1907, 1909) with metal wires and later by Townsend and Vickery (1967) and Nunn and Rowell (1967) with single objects were in some cases very much slower than expected. The discrepancy was greatest for objects which had a high thermal conductivity. Nye (1967) has discussed the possible reasons for the anomalous results found in the recent work and he proposed supercooling and/or superheating at the ice-water interface as the most likely cause of the anomaly. Frank (1967) added the suggestion that the instability of the freezing surface behind wires of high thermal conductivity could produce the required reduction in the velocity of regelation.

Two independent (but essentially identical) analyses of the regelation process have been carried out by Ornstein ( 1906$)$ and Nye ( 1967$)$. These analyses were extended by Drake and Shreve (1973) as part of an experimental study which they carried out and which involved 
wires. They found that at a certain value of the applied force there was a marked change in the behaviour of the system. Above a transition force their results agreed with those of Nunn and Rowell; for example, the velocity of a copper wire, a material with a high thermal conductivity, was up to 8 times less than the velocity predicted by the basic theory whereas the velocity of a nylon wire (low thermal conductivity) was as predicted. Below the transition point, however, the velocities of all wires were less than expected. The velocity of the copper could be up to 500 times smaller and that of the nylon up to 14 times smaller than the theory predicted.

When the force applied to the wire is small and the transition value has not been exceeded, the pressure at points ahead of the moving wire (point $P$ in Fig. I (a)) will be greater than atmospheric whereas the pressure at points behind the wire ( $Q$ in Fig. $\mathrm{r}(\mathrm{a})$ ) will be lower than atmospheric. These deviations from atmospheric pressure are equal in magnitude but opposite in sign and so the pressure in the water layer can be seen to vary about a mean value which is equal to the atmospheric pressure. The temperature of the ice-water interface is proportional to the pressure and so varies about a mean temperature equal to the melting temperature of ice at atmospheric pressure. If the ice as a whole is immersed in an ice-water mixture the outer surface will also be at the melting point. Thus, for applied forces which do not exceed the transition value, the mean temperature of the water layer is equal to the melting temperature of the ice.

(a)

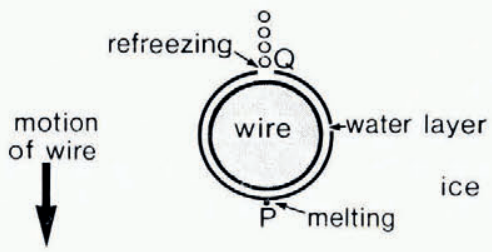

(b)

movement of ice

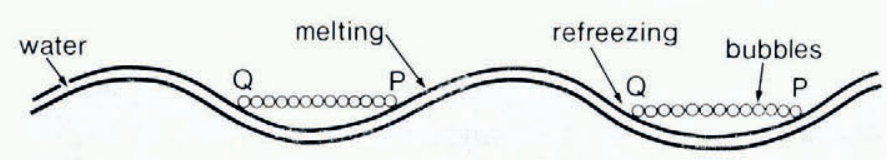

(c)

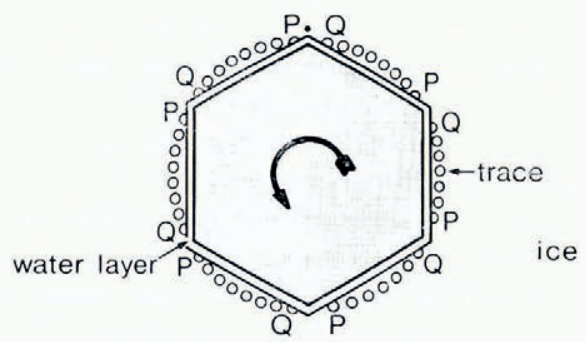

Fig. I. (a) A round wire moving through ice by the process of regelation. (b) Ice moving over a simple sine-wave bed by regelation and plastic flow. (c) A regular hexagonal cylinder rotating in ice by regelation and plastic flow. 
As the applied force increases, the water pressure at point $Q$ decreases until it eventually reaches the triple-point pressure. The water pressure in the layer behind the wire cannot be less than the triple-point pressure so that if the applied force is increased further the mean pressure in the layer as a whole must increase. Above the transition point this mean pressure is greater than atmospheric pressure and, if the outer surface of the ice is at the melting point, the mean temperature is lower than the ambient temperature. As a result of this temperature gradient, heat flows towards the wire and produces extra water which flows to the lowpressure region behind the wire where it is shed as a trace (Fig. I (a)).

The very low velocities below the transition point are attributed by Drake and Shreve to the presence of accumulated solutes in the water layer around the wire. Ionic and gaseous impurities are released into the water layer as the ice melts in front of the wire and they are then carried by the water to the rear of the wire where they are rejected into solution by the freezing process. Here they depress the melting point and inhibit refreezing. The rate of dispersal of the impurities by diffusion is too slow to reduce this impurity concentration gradient significantly (Lliboutry, I97I ; Drake and Shreve, I973; Morris, unpublished). If less water is frozen behind the wire, less latent heat is available for melting in front of the wire so that its speed through the ice is reduced.

Above the transition point, on the other hand, the impurities are carried away from the water layer in the trace. There is no concentration of impurities behind the wire and the regelation velocity is not reduced through lack of latent heat. Drake and Shreve attribute the differences between observed and predicted regelation velocities above the transition point to the effect of supercooling (following Nye) and to the presence of the trace.

\section{(b) The Nye theory of basal sliding}

The theory of basal sliding developed by Nye (1969, 1970) is concerned with the motion of ice over a series of obstacles by both regelation and plastic flow. He derives an expression for the velocity of basal sliding in terms of the average drag on the bed after making the following assumptions:

(a) the ice may be treated as a Newtonian viscous liquid

(b) the slope of the bed is everywhere small

(c) there is a thin water layer between the ice and the bed rock

(d) the temperature difference across this water layer is negligible

(e) the effects of heat sources and sinks within the ice are negligible.

In a later paper Nye (1973) comments upon the implications of the work of Drake and Shreve for his theory of basal sliding. He suggests that over most of the bottom of a glacier the pressure on the down-stream side of an obstacle will not reach the triple point so that, as in the experiments of Drake and Shreve below the transition point, the effect of impurities in the water layer may dominate the melting and refreezing process. However, there is a fundamental difference between the two geometries which must be taken into account. Figure I (b) represents ice flowing over a bed which has the form of a simple sine wave. The highest pressure in the water layer separating ice and rock occurs at up-stream points $P$, the lowest at down-stream points $Q$. Any excess water shed into the ice at points $Q$ returns to the water layer at the next point of high pressure. Since water is not lost from the system a heat flow to the ice-water interface is not required to maintain the trace. In this geometry it is possible for a dense trace to exist below the transition point. Thus, both above and below the transition point, solutes may be removed from the water layer so that there is no accumulation of impurities at down-stream points and the regelation velocity is not reduced through lack of latent heat. There need not be a sudden change in regelation velocity at the transition point whatever the average concentration of impurity. 


\section{(c) The viscometer experiment}

In the experiment reported here the flow of a glacier over its bed is represented by the rotation in ice of a cylinder about its longitudinal axis. A cylinder with a non-circular crosssection represents a rough glacier bed. Three different cylinders were used in these experiments, one had the cross-section of a "sine wave", another that of a hexagon, and the third had an octagonal shape. Figure I (c) shows the cylinder with a regular hexagonal cross-section rotating in a fixed ice block. The high- and low-pressure points are again marked $\mathrm{P}$ and $\mathrm{Q}$ respectively. Traces are shown to extend from each point $Q$ to the point $\mathrm{P}$ immediately down-stream. Such traces were observed during the experiment.

The surfaces of the brass cylinders used in the experiment belong to the set of surfaces represented by the equation

$$
r_{0}=R_{N}+\sum_{n=1}^{\nu} \phi_{N n} \cos (n \mathcal{N} \theta)
$$

where $r, \theta$ are polar coordinates and $n, \nu$ and $\mathcal{N}$ are integers. The sine-wave cylinder has $R_{N}=45 \mathrm{~mm}, \mathcal{N}=8$ and $\phi_{N n}=2 \mathrm{~mm}$ when $n=\mathrm{I}$ and $\phi_{N n}=0$ for al $\mathrm{l} n>\mathrm{I}$. For the hexagonal $(\mathcal{N}=6)$ and octagonal $(\mathcal{N}=8)$ cylinders $\phi_{N n}$ and $R_{N}$ are given by the equations

$$
\begin{aligned}
\phi_{N n} & =\frac{4^{R_{N}{ }^{\prime} \mathcal{N}}}{\pi} \cos \left(\frac{\pi}{\mathcal{N}}\right)(-\mathrm{I})^{N n / 2} \sum_{k=\frac{\mathcal{N} n}{2}}^{\infty}(-\mathrm{I})^{k-\mathrm{I}} \frac{\sin (2 k-\mathrm{I})^{\pi / N}}{(2 k-\mathrm{I})}, \\
R_{N} & =\frac{R_{N}{ }^{\prime} \mathcal{N}}{2 \pi} \cos \left(\frac{\pi}{\mathcal{N}}\right) \ln \left\{\frac{\mathrm{I}+\sin \pi / \mathcal{N}}{\mathrm{I}-\sin \pi / \mathcal{N}}\right\} .
\end{aligned}
$$

$R_{N}{ }^{\prime}$ is the radius of the circumscribing cylinder and is equal to $25 \mathrm{~mm}$ in both cases. The Fourier series are terminated at $n=v$. At this point the termination error is of the same order as the error involved in machining the cylinders.

(i) The relative importance of each sliding mechanism in the viscometer experiment

The average drag $\left\langle\tau_{r \theta}\right\rangle$ on a cylinder rotating in ice with angular velocity $\omega$ may be calculated using the sliding theory of Nye ( 1969 ) transformed into polar coordinates. If the surface is represented by Equation (I) then

$$
\left\langle\tau_{r \theta}\right\rangle=\frac{\eta \omega n_{*}^{2}}{R_{N^{2}}} \sum_{n=\mathrm{I}}^{\nu} \phi_{N n^{2}} \frac{n \mathcal{N}\left(n^{2} \mathcal{N}^{2}-\mathrm{I}\right)}{\left(n_{*}^{2}+n^{2} \mathcal{N}^{2}-\mathrm{I}\right)} .
$$

$\eta$ is the supposed viscosity of the ice and $n_{*}$ is a spatial frequency related to Nye's critical wavelength $\lambda_{*}$ by the equation

$$
n_{*}=2 \pi R_{N} / \lambda_{*} .
$$

Thus $n_{*}$ is the number of times the critical wavelength fits into the circumference of the cylinder. Its value for a particular cylinder may be calculated from the equation

$$
n_{*}^{2}=L R_{N}{ }^{2} /(4 C K \eta)
$$

where $L$ is the latent heat of fusion of ice per unit volume, $K$ the average thermal conductivity of the ice and the cylinder, and $C$ the depression of the freezing point per unit pressure. 
When $n^{2} \mathcal{N}^{2} \ll n_{*}{ }^{2}$ for $\mathrm{I} \leqslant n \leqslant \nu$, that is, for large obstacles, Equation (2) becomes

$$
\left\langle\tau_{r \theta}\right\rangle=\frac{\eta \omega}{R_{N}{ }^{2}} \sum_{n=1}^{\nu} \phi_{N} n^{2} n \mathcal{N}\left(n^{2} \mathcal{N}^{2}-\mathrm{I}\right) .
$$

The dominant sliding mechanism is plastic flow and the thermal constants $L, K$ and $C$ do not appear in the equation.

When $n^{2} \mathcal{N}^{2} \gg n_{*}^{2}$ for $\mathrm{I} \leqslant n \leqslant \nu$ the equation becomes

$$
\left\langle\tau_{r \theta}\right\rangle=\frac{L \omega}{{ }_{4} C K} \sum_{n=1}^{\nu} \phi_{N} n^{2} n \mathcal{N} .
$$

For small obstacles regelation is the dominant sliding mechanism and the viscosity $\eta$ does not appear in the equation.

The maximum average shear stress applied to the surfaces of the cylinders during the viscometer experiments was $5 \times 10^{4} \mathrm{~Pa}$. From Glen's law the "viscosity" of ice may be estimated to be about ${ }^{1} \mathrm{O}^{14} \mathrm{P}$ at this stress. Thus, in these experiments the critical spatial frequency $n_{*}$ was about $10^{-2}$. The spatial frequencies $n \mathcal{N}$, are all very much larger than this. Thus regelation was the dominant sliding mechanism in our experiments.

\section{(ii) Permissible surfaces}

There are some surfaces represented by Equation (I) for which Equation (2) is not valid (Nye, 1973). The flow of water in the regelation layer is

$$
q=\frac{\rho_{\mathrm{i}}}{\rho_{\mathrm{W}}} \omega R_{N} \sum_{n=\mathrm{I}}^{\nu} \frac{\left(n^{2} \mathcal{N}^{2}-\mathrm{I}\right)}{\left(n_{*}^{2}+n^{2} \mathcal{N}^{2}-\mathrm{I}\right)} \phi_{N n} \cos (n \mathcal{N} \theta)
$$

where $\rho_{\mathrm{i}}$ and $\rho_{\mathrm{w}}$ are the densities of ice and water respectively. The pressure gradient in the water layer is

$$
\frac{\mathrm{I}}{R_{N}} \frac{\mathrm{d} p}{\mathrm{~d} \theta}=-2 \eta \omega \frac{n_{*}^{2}}{R_{N^{2}}} \sum_{n=1}^{\nu} \frac{\left(n^{2} \mathcal{N}^{2}-\mathrm{I}\right) n \mathcal{N}}{\left(n_{*}^{2}+n^{2} \mathcal{N}^{2}-\mathrm{I}\right)} \phi_{N n} \cos (n \mathcal{N} \theta) .
$$

Now $q$ and $-\frac{\mathrm{I}}{R_{N}} \frac{\mathrm{d} p}{\mathrm{~d} \theta}$ should have the same sign for all $\theta$ since the water must flow down the pressure gradient. That is, the set of solutions of

$$
\sum_{n=1}^{\nu} \frac{\left(n^{2} \mathcal{N}^{2}-\mathrm{I}\right)}{\left(n_{*}^{2}+n^{2} \mathcal{N}^{2}-\mathrm{I}\right)} \phi_{N n} \cos (n \mathcal{N} \theta)=0
$$

should be identical to the set of solutions of

$$
\sum_{n=1}^{v} \frac{\left(n^{2} \mathcal{N}^{2}-\mathrm{I}\right) n \mathcal{N}}{\left(n_{*}^{2}+n^{2} \mathcal{N}^{2}-\mathrm{I}\right)} \phi_{N n} \cos (n \mathcal{N} \theta)=0
$$

This criterion evidently restricts the allowed values of $\phi_{N} n$.

If all coefficients $\phi_{N n}$ except one are zero, the solutions of Equations (4) and (5) are the same. Thus the surfaces with only one Fourior component are permissible. 
Equations (4) and (5) are the real parts of equations

$$
\sum_{n=1}^{v} \frac{\left(n^{2} \mathcal{N}^{2}-1\right) \phi_{N n} z^{n}}{\left(n_{*}^{2}+\mathcal{N}^{2} n^{2}-\mathrm{I}\right)}=0
$$

and

$$
\sum_{n=1}^{v} \frac{\left(n^{2} \mathcal{N}^{2}-\mathrm{I}\right) n \mathcal{N} \phi_{N n} z^{n}}{\left(n_{*}^{2}+\mathcal{N}^{2} n^{2}-\mathrm{I}\right)}=0
$$

where $z=\exp (i \mathcal{N} \theta)$. Equation (6) has no non-zero roots in the allowed range of $z,(z \mid z \bar{z}=\mathrm{I})$, if the coefficients $\phi_{N n}$ obey the conditions

$$
\left|\frac{\left(\mathcal{N}^{2} n^{2}-\mathrm{I}\right)\left(n_{*}^{2}+\mathcal{N}^{2} \nu^{2}-\mathrm{I}\right) \phi_{N n}}{\left(\mathcal{N}^{2} \nu^{2}-\mathrm{I}\right)\left(n_{*}^{2}+\mathcal{N}^{2} n^{2}-\mathrm{I}\right) \phi_{N \nu}}\right|>{ }^{\nu-1} C_{\nu-n}
$$

(see, for example, Rektorys ( 1969, p. 76) on the properties of the roots of algebraic equations). The symbol ${ }^{\nu-1} C_{\nu-n}$ represents the numbers of combinations of $(\nu-1)$ different elements taken $(\nu-n)$ at a time. Similarly, Equation (7) has no roots if the coefficients obey the conditions

$$
\left|\frac{\left(\mathcal{N}^{2} n^{2}-\mathrm{I}\right)\left(n_{*}^{2}+\mathcal{N}^{2} \nu^{2}-\mathrm{I}\right) n \phi_{N n}}{\left(\mathcal{N}^{2} \nu^{2}-\mathrm{I}\right)\left(n_{*}^{2}+\mathcal{N}^{2} n^{2}-\mathrm{I}\right) \nu \phi_{N \nu}}\right|>{ }^{\nu-1} C_{\nu-n} .
$$

When $n^{2} \mathcal{N}^{2} \gg n_{*}^{2}$ these conditions reduce to:

$$
\left|\frac{\phi_{N n}}{\phi_{N \nu}}\right|>{ }^{\nu-1} C_{\nu-n}
$$

and

$$
\left|\frac{n \phi_{N n}}{\nu \phi_{N \nu}}\right|>{ }^{\nu-1} C_{\nu-n} .
$$

If Equations (6) and (7) have no non-zero roots in the allowed range of $z$ then the only solutions of (4) and (5) in the range $-\pi / \mathcal{N}$ to $\pi / \mathcal{N}$ will be at $\pm \pi / 2 \mathcal{N}$. The solutions of each equation are the same and the surface is permissible. Thus, a surface is permissible if the Fourier coefficients decrease quickly enough for the above inequalities to hold. A surface shape that is allowed on the small scale may become impermissible on a larger scale when plastic flow becomes important.

There will be non-zero roots when, for any $n$,

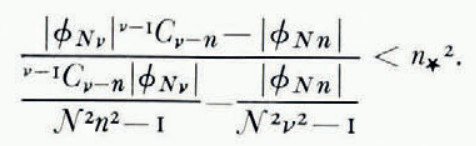

This inequality will certainly hold for $n=\mathrm{I}$ if $n_{*}^{2}>\mathcal{N}^{2}-\mathrm{I}$.

Thus, if the fundamental spatial frequency $\mathcal{N}$ is less than $\left(n_{*}^{2}+1\right)^{\frac{1}{2}}$, the surface is not permissible. So that, although the surfaces of the brass cylinders of radius $R_{N} \approx 25 \mathrm{~mm}$ which were used in the experiment are permissible, the surfaces of cylinders of the same shape but of radius $R_{N} \gtrsim 25 \mathrm{~mm}$ are not.

The difficulties that lead to certain shapes not being permissible can be resolved if the temperature drop across the water layer is taken fully into account (Nye, I973). It is probable that similar difficulties in the glacier geometry would also disappear if the theory of basal sliding were refined in the same way. 


\section{(iii) The temperature distribution}

If the mean temperature at the ice-water interface is equal to the ambient temperature on the outer surface of the ice, the temperature distribution in the ice and cylinder may be divided into two components: the "regelation" temperature distribution $\mathcal{T}_{\mathrm{r}}(r, \theta)$, and a second component $T_{\mathrm{i}}(r, \theta)$, which arises from the presence of internal sources and sinks of heat. $T_{\mathrm{r}}(r, \theta)$ is defined to be the solution of the Laplace equation with the Neumann boundary condition given by the distribution of sources and sinks of heat on the inner surface of the ice. $T_{\mathrm{i}}(r, \theta)$ is then the solution of a Poisson equation with the Neumann boundary condition

$$
\frac{\mathrm{d} T_{\mathrm{i}}}{\mathrm{d} r}=\mathrm{o} \quad \text { at } r=R_{N} .
$$

Thus,

$$
T(r, \theta)=\mathcal{T}_{\mathbf{r}}(r, \theta)+T_{\mathbf{i}}(r, \theta) \quad \text { for } r \geqslant R_{N}
$$

and in the cylinder

$$
T(r, \theta)=T_{\mathbf{r}}(r, \theta)+T_{\mathrm{i}}\left(R_{N}, \theta\right) \quad \text { for } r \leqslant R_{N} .
$$

For surfaces represented by Equation (I) the regelation temperature is given by the equations

$$
\begin{array}{ll}
T_{\mathrm{r}}(r, \theta)=\frac{L R_{N} \omega}{2 K} \sum_{n=1}^{\nu} \phi_{N}\left(\frac{R_{N}}{r}\right)^{n} \sin (n \mathcal{N} \theta)+T_{\mathrm{m}}, \quad r \geqslant R_{N} \\
T_{\mathrm{r}}(r, \theta)=\frac{L R_{N} \omega}{2 K} \sum_{n=1}^{\nu} \phi_{N}\left(\frac{r}{R_{N}}\right)^{n} \sin (n \mathcal{N} \theta)+T_{\mathrm{m}}, \quad r \leqslant R_{N}
\end{array}
$$

where $T_{\mathrm{m}}$ is the mean temperature and $r$ and $\theta$ refer to axes fixed with respect to the cylinder. $T_{\mathrm{i}}$ is unknown and $T_{\mathrm{i}}\left(R_{N}, \theta\right)$ has hitherto been supposed to be negligible compared to $T_{\mathrm{r}}(R, \theta)$.

As the cylinder rotates, the value of $\theta$, and hence the temperature, will change for each point in the ice. If the temperature difference between two points on the radius $r=r^{\prime}$ and separated by an angle of $\pi / \mathcal{N}$ is plotted as a function of time the resulting curve will have an amplitude twice that of the temperature distribution curve $T\left(r^{\prime}, \theta\right)$.

\section{Apparatus}

Figure 2 shows the viscometer. A cylinder A was keyed onto a stainless-steel shaft B. This shaft was supported by bearings $\mathrm{c}$ which were located in the top and bottom plates of the viscometer chamber D and were protected by water seals. The slides of the chamber were lined by four "Tufnol" plates $\mathrm{E}$ each resting against four bolts through the side walls of the chamber. While an experiment was in progress the bolts could be tightened against the pressure plates in order to hold the specimen firmly even if melting had occurred on its outer surface. Lead weights on the weight holder $\mathrm{F}$ provided a torque on the shaft via the sprocket and chain $\mathrm{G}$, the horizontal shaft $\mathrm{H}$, and the bevel gear $\mathrm{I}$. The centre of gravity of the weights was kept directly below the support to reduce friction. Two sprocket teeth welded to the back of the carrier were held in the links of the chain by a back-plate $\mathrm{J}$. In this way, the weight carrier could be detached from the chain when no torque was required and reattached at any one of the links. The relationship between the torque acting on the cylinder and the weight of lead was established by calibration experiments. 

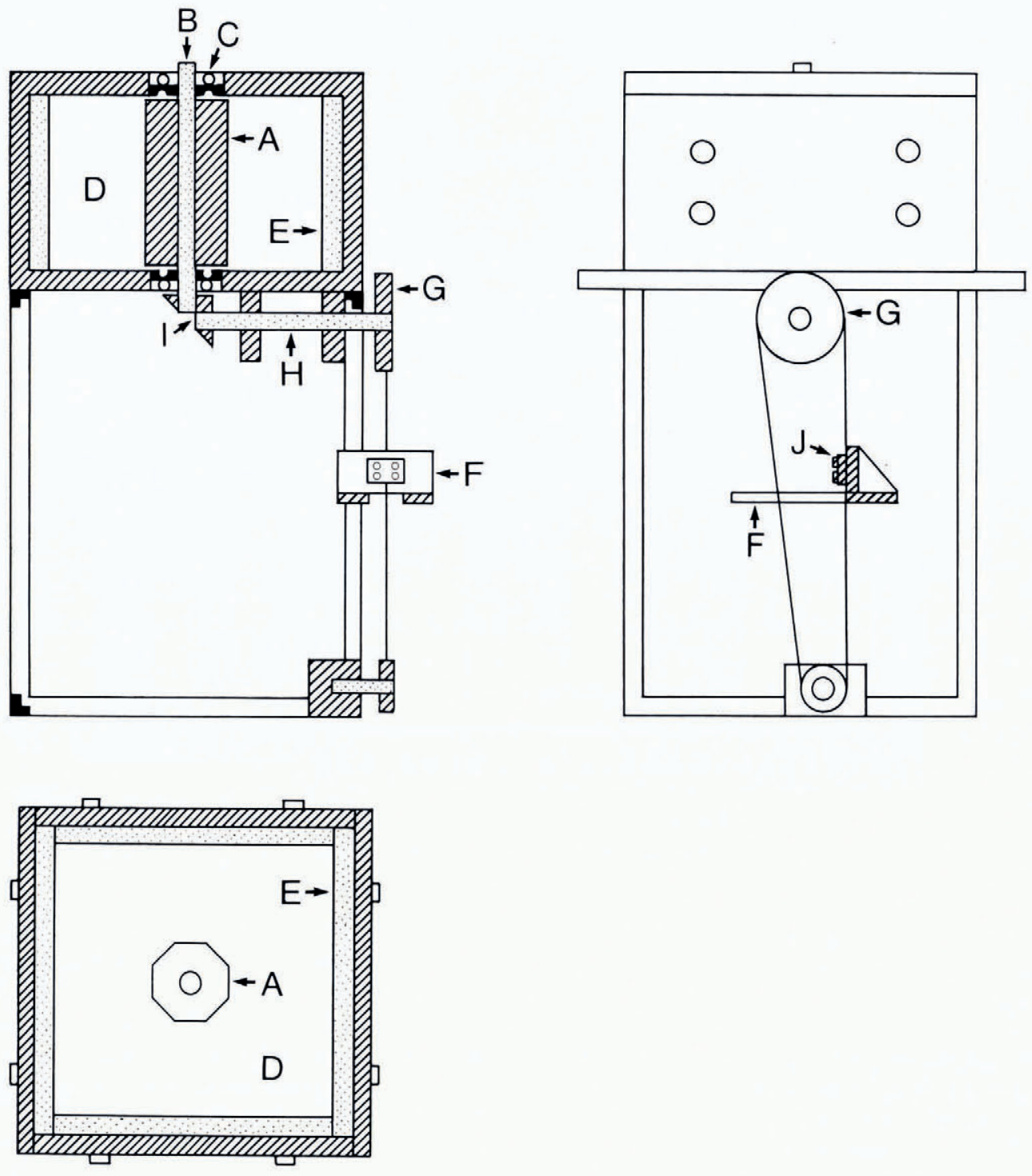

Fig. 2. The viscometer used in these experiments.

A nylon rod keyed to the top of the viscometer shaft drove a pinion to which a pointer was attached. The movement of the tip of the pointer was measured using a travelling microscope. In addition, the rotation of the pinion was magnified by a gear train which had a very low frictional resistance. Each complete revolution of the final pinion was recorded as a voltage pulse by a chart recorder.

Ice was grown around the cylinder by a method developed from that of Barnes (unpublished). The apparatus is shown in Figure 3. The brass freezing chamber $\mathrm{A}$ had a diameter of $229 \mathrm{~mm}$ and was $267 \mathrm{~mm}$ deep. There was a vacuum-tight "O-ring" seal в between the lid $\mathrm{c}$ and the rim of the chamber; the rim and the lid were held together by clamps $\mathbf{D}$. 


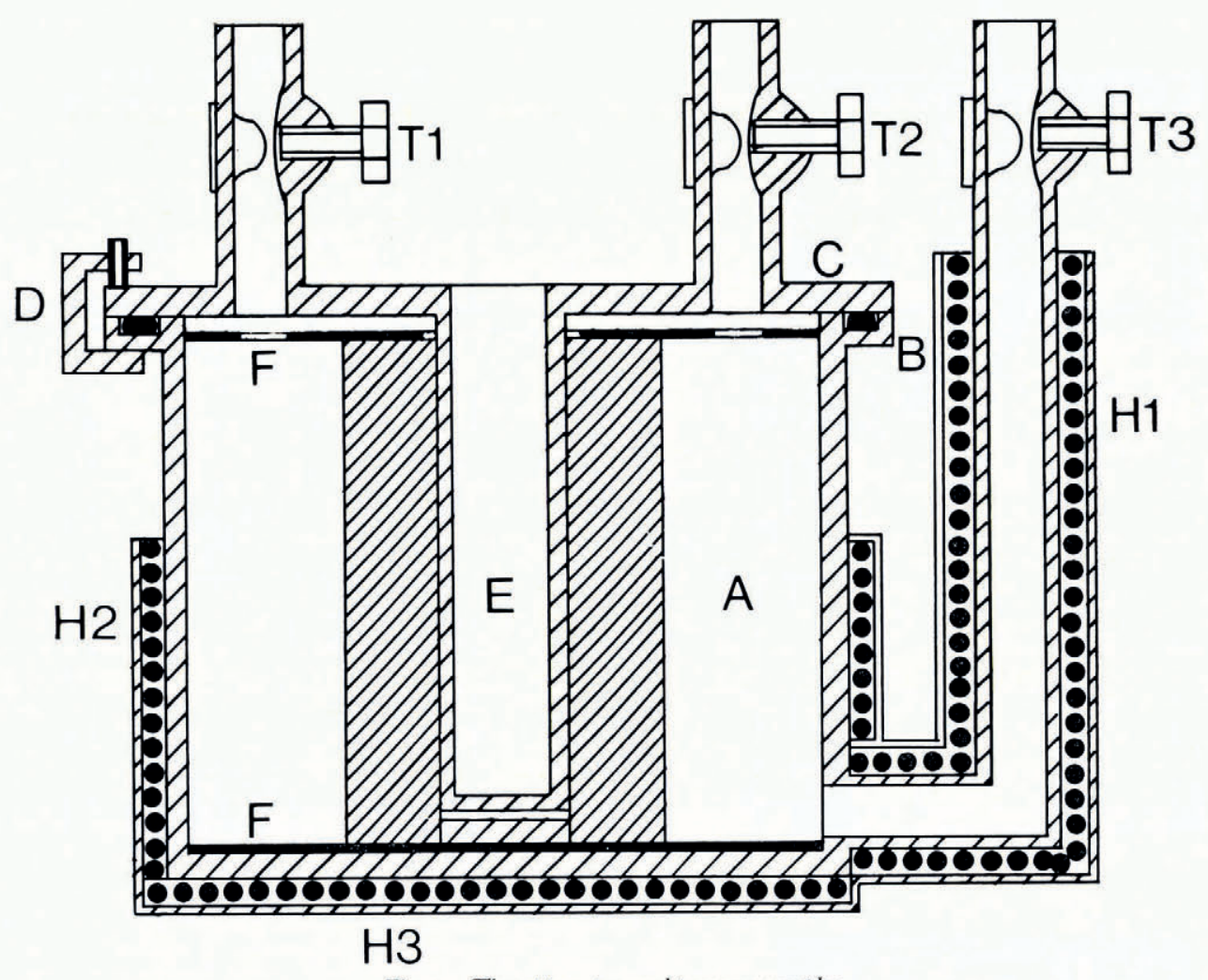

Fig. 3. The apparatus used to grow samples.

A hollow cold-finger $\mathrm{E}$ of the same diameter as the viscometer shaft extended downwards from the centre of the lid. The apparatus was heated by three coils, $\mathrm{H}_{\mathrm{I}}, \mathrm{H}_{2}$ and $\mathrm{H}_{3}$. Three brass tubes leading into the apparatus were closed by vacuum taps, $\mathrm{T}_{1}, \mathrm{~T}_{2}$ and $\mathrm{T}_{3}$. The escape tube $\left(\mathrm{T}_{3}\right)$ was also sealed by a rubber balloon. A thermocouple frame $\mathrm{F}$ consisted of two circular plates held apart by three detachable rods. The top plate had a central hole through which the cold finger could just pass, the bottom plate had a central metal boss. The cylinder fitted tightly onto the cold-finger and the boss. A pattern of fine holes was drilled in the two plates and a thermoelectric junction (which consisted of copper and constantan wires welded together), was strung tautly between each pair of holes.

The apparatus was placed near to the top of a refrigerator and a low-pressure distillation system was arranged to run double-distilled water into the freezing chamber through tap $\mathrm{T}_{\mathrm{I}}$. When the apparatus was full of water, taps $T_{1}$ and $T_{2}$ were closed and $T_{3}$ opened, the heating coils were switched on, and the sample was allowed to freeze. Freezing proceeded outwards from the unheated metal surface into the water. Ionic impurities and dissolved air were rejected by the ice and, when the freezing process had finished, it was found that a small residue of impurity had become concentrated in a thin surface at the centre of the ice annulus, and also in the water which remained in the balloon and escape tube. The frozen sample was removed and the constantan ends of the thermocouple junctions were soldered together to form a rail at the bottom of the ice. The cylinder, with its surrounding ice annulus, was fitted onto the shaft of the viscometer which had already been cooled in a refrigerator to $-20^{\circ} \mathrm{C}$. Crushed ice, frozen from distilled water, was packed around the sample and distilled 
water at $0^{\circ} \mathrm{C}$ was poured very slowly into the viscometer chamber until a complete sample had been made. The ends of the copper wires were connected to a voltmeter through a switching system. Plastic boxes containing a mixture of distilled water and ice were packed around the viscometer and the required selection of weights arranged on the weight holder. The temperature of the sample was allowed to rise

\section{RESUlts}

The major problem encountered in these experiments was the control of the ambient temperature. If regelation is to occur over a reasonable length of time the ambient temperature must be very close to the appropriate mean temperature otherwise heat flow towards the cylinder will cause bulk melting which can very quickly affect the regelation process. Excess water remaining in a trace left behind a single object which is being pulled through ice has no further effect on the system, but water in a trace surrounding a cylinder remains within the system. As heat flow towards the cylinder continues, the amount of water stored in the trace increases until the obstacles are swamped and the cylinder is free to rotate without resistance from the ice. Thus, temperature control is more important in this experiment than in the traditional regelation experiments. Ideally the ambient temperature should be equal to the mean temperature $T_{m}$ which depends on the particular torque applied to the cylinder and the concentration of impurity in the ice. In practice, small fluctuations $(\approx \pm 2 \mathrm{mK})$ in ambient temperature occur with the same period as the control cycle of the refrigerator and the mean ambient temperature is not exactly equal to $T_{\mathrm{m}}$. The smaller the difference between the two temperatures the longer the period of regelation can be.

During these experiments there were three stages, during which the angular velocity of the cylinder first of all increased slowly, then remained constant and finally increased rapidly. Figure 4 shows, for example, the variation in angular velocity of the octagonal cylinder during experiment A. We identify these stages as the incubation and regelation periods of previous workers (e.g. Townsend and Vickery, 1967) and as a period during which bulk melting is dominant. Table I shows the velocity of the cylinder relative to the ice during the regelation stage, the duration of the regelation stage and other parameters for eight experiments. Experiments $\mathrm{E}, \mathrm{F}$ and $\mathrm{K}$ were terminated before the onset of bulk melting. This was achieved by reducing the refrigerator temperature. The rest of the experiments were allowed to continue

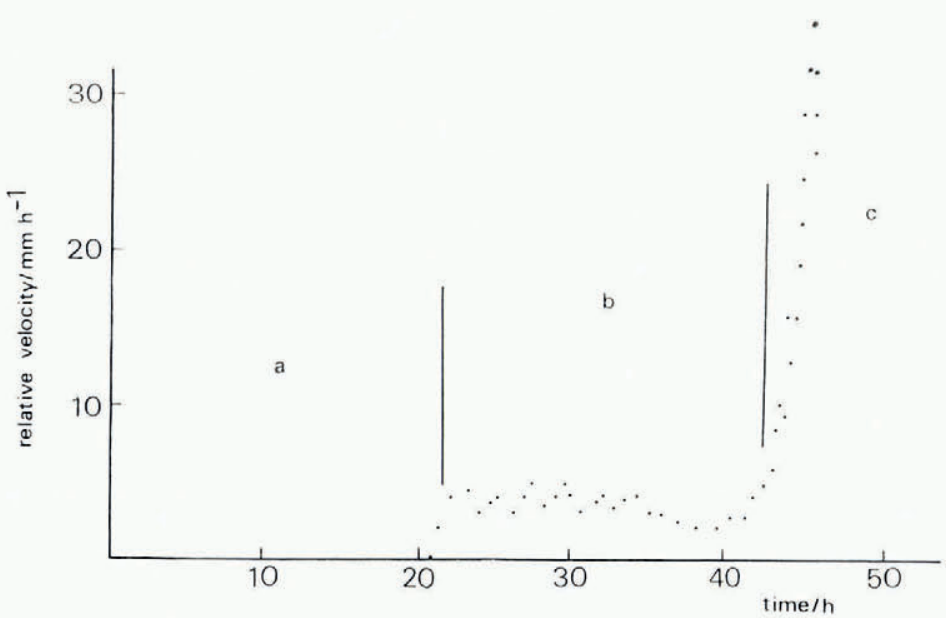

Fig. 4. The variation of the relative velocity between ice and the cylinder with time during experiment $A$. 
Table I. The relative velocity of the cylinder during the Regelation stage, and the DURATION OF REGELATION

\begin{tabular}{|c|c|c|c|c|c|}
\hline Experiment & $\begin{array}{l}\text { Cylinder } \\
\text { shape }\end{array}$ & $\begin{array}{l}\text { Average shear } \\
\text { stress on the } \\
\text { surface } \\
\times 10^{5} \mathrm{~Pa}\end{array}$ & $\begin{array}{l}\text { Relative } \\
\text { velocity } \\
\mathrm{mm} \mathrm{h}^{-1}\end{array}$ & $\begin{array}{c}\text { Duration of } \\
\text { regelation } \\
\mathrm{h}\end{array}$ & $\begin{array}{l}\text { Displacement of cylinder } \\
\text { during regelation period / } \\
\text { obstacle wavelength } \\
\quad 2 \pi R_{N} / \mathcal{N}\end{array}$ \\
\hline A & Octagonal & $0.444 \pm 0.006$ & $3 \cdot 5^{\circ} \pm 1.5^{\circ}$ & 21.0 & 3.8 \\
\hline B & Octagonal & $0.444 \pm 0.006$ & $5 \cdot 5^{\circ} \pm \mathbf{1} .00$ & 1.0 & 0.3 \\
\hline C & Octagonal & $0.444 \pm 0.006$ & $5.00 \pm 0.50$ & 1.2 & 0.3 \\
\hline E & Hexagonal & $0.388 \pm 0.005$ & $2.45 \pm 0.68$ & 3.0 & 0.3 \\
\hline $\mathrm{F}$ & Hexagonal & $0.3^{88} \pm 0.005$ & $1.80 \pm 0.90$ & 11.0 & 0.8 \\
\hline G & Sine wave & $0.123 \pm 0.002$ & $2.83 \pm 0.06$ & I. 6 & 0.1 \\
\hline $\mathrm{H}$ & Sine wave & $0.123 \pm 0.002$ & $\mathrm{r} .50 \pm \mathrm{r} .00$ & 10.0 & 0.4 \\
\hline $\mathrm{K}$ & Sine wave & $0.123 \pm 0.002$ & $1.30 \pm 0.10$ & 2.2 & 0.1 \\
\hline
\end{tabular}

into the bulk-melting stage. Figure 5 shows these experimental regelation velocities plotted against the expected regelation velocities calculated from Equation (3). Some results obtained by Nunn and Rowell (1967) with carbon-steel wires of similar conductivity ( $K=33$ $\mathrm{J} \mathrm{m}^{-1} \mathrm{~s}^{-1} \mathrm{~K}^{-1}$ for ice and carbon-steel, $K=67 \mathrm{~J} \mathrm{~m}^{-1} \mathrm{~s}^{-1} \mathrm{~K}^{-1}$ for our cylinders) are also shown for comparison. The driving stresses for their experiments 6, 6A, 7 and $7 \mathrm{~A}$ were $0.28,0.54,0.46$ and $0.23 \mathrm{MPa}$ respectively. Thus, all these experiments were performed at stresses above the transition level. The same discrepancy between the theoretical and observed regelation velocities appears in our experiments $\mathrm{A}$ to $\mathrm{K}$ and in the experiments of Nunn and Rowell.

In our experiments the ice contains approximately 2 p.p.m. NaCl-equivalent impurity. A solution of the regelation equations for the simple sine-wave bed in the presence of a very

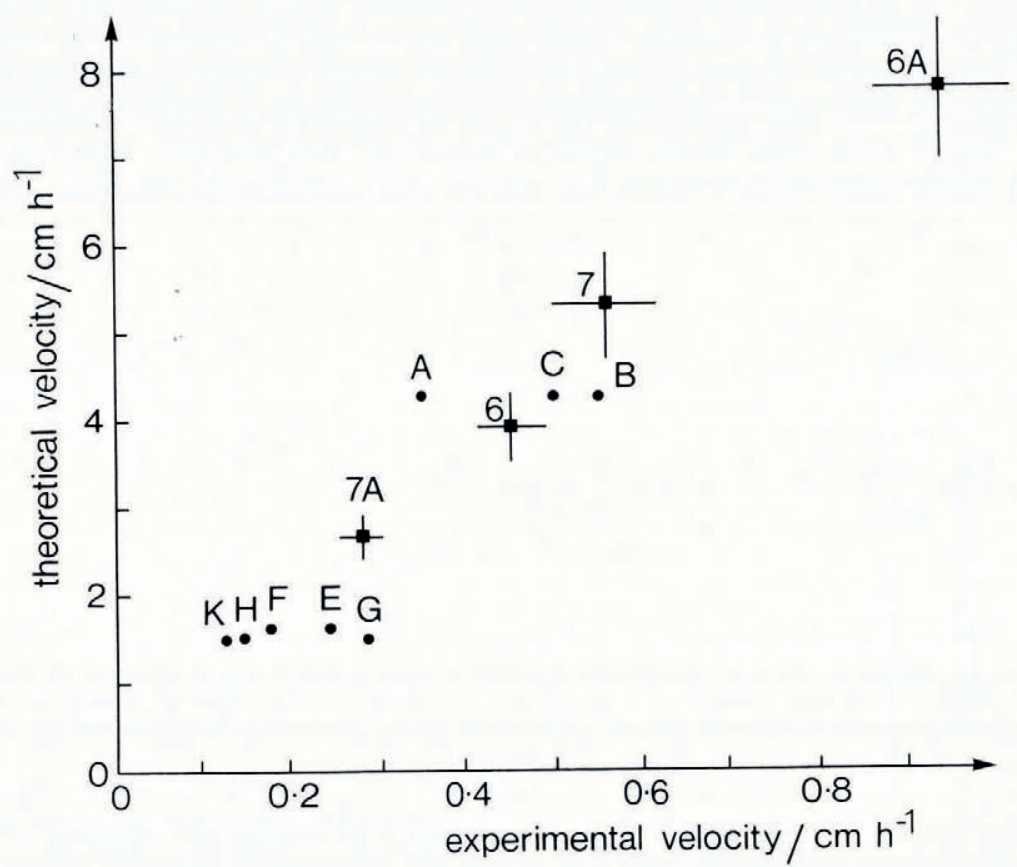

Fig. 5. A comparison of predicted and measured regelation velocities. Points $A$ to $K$ refer to experiments carried out with brass cylinders, points 6, 6. 7 and 7A to the experiments of Nunn and Rowell which employed carbon-steel wires. 
small amount of impurity has been derived using perturbation analysis (Morris, unpublished). We use this solution to estimate the average shear stress on the sine-wave cylinder at the lower transition limit for an average concentration $c_{\text {av }}$ of 2 p.p.m. NaCl equivalent. At the DrakeShreve lower transition limit the pressure distribution is approximately

$$
p=\frac{\left(T_{0}-T^{\prime}\right)}{C} \sin \mathcal{N} \theta+\frac{A^{\prime}}{C} c_{\mathrm{av}}\left\{\mathrm{I}+\left[\frac{\exp (-\mu \sin \mathcal{N} \theta)}{\exp (-\mu)}\right](-2 \pi \mu)^{\frac{1}{2}}\right\}
$$

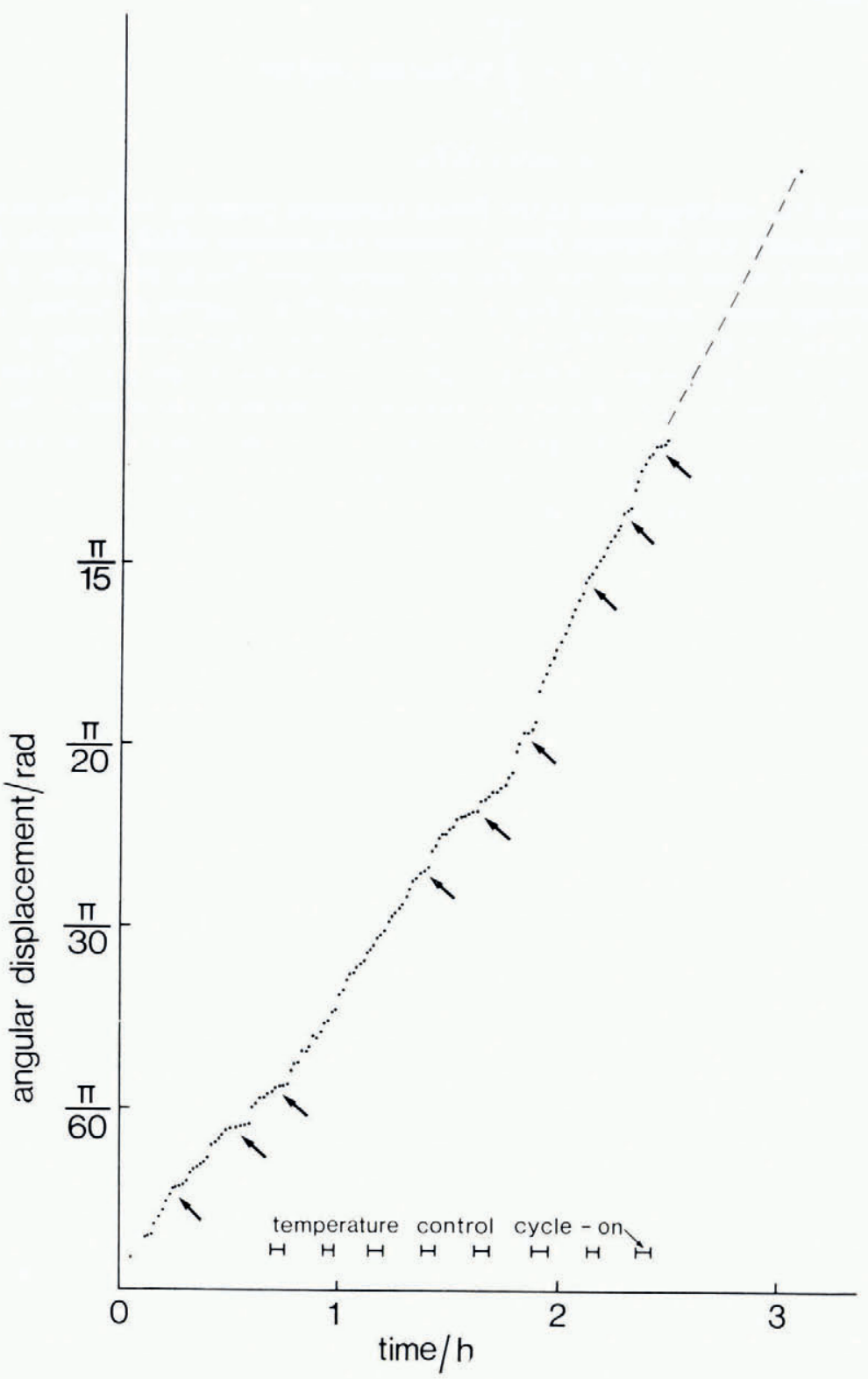

Fig. 6. The displacement of the hexagonal cylinder as a function of time during the regelation stage (experiment F) 
where $T^{\prime}$ is the triple-point temperature and $T_{0}$ the temperature of the melting point at atmospheric pressure. The constant $\mu$ is given by the equation

$$
\mu=\frac{2 K}{\alpha} \frac{\rho_{\mathrm{i}}}{\rho_{\mathrm{w}}} \frac{R_{N}}{\mathcal{N} D}\left[T_{0}-T^{\prime}\right]\left\{\frac{24 \eta_{\mathrm{w}} K \rho_{\mathrm{i}} C R_{N}}{\alpha \rho_{\mathrm{w}} \mathcal{N}}\right\}^{-\frac{1}{2}}
$$

where $\eta_{\mathrm{w}}$ is the viscosity of water, $\rho_{\mathrm{i}}$ and $\rho_{\mathrm{w}}$ are the densities of ice and water respectively and $D$ is the diffusion constant for the impurity. The average shear stress on the surface of the cylinder is then

$$
\begin{aligned}
\langle\tau\rangle & \approx-\int_{-\pi / \mathcal{N}}^{\pi / \mathcal{N}} p \mathcal{N} \phi_{N} \sin (\mathcal{N} \theta) \mathrm{d} \theta \\
& \approx 0.025 \mathrm{MPa} .
\end{aligned}
$$

Rough estimates of the average stress at the lower transition point for both the octagonal and the hexagonal cylinders are obtained from a similar calculation which uses the first term of their representative Fourier series only. The estimated stress lies in the range $0.2-0.25 \mathrm{~Pa}$. The applied average shear stresses are below the estimated average shear stresses at the lower transition point in experiments $\mathrm{G}, \mathrm{H}$ and $\mathrm{K}$ and above this value in experiments $\mathrm{A}$ to $\mathrm{F}$.

Figure 6 shows the displacement of the hexagonal cylinder as a function of time during the regelation stage of experiment $\mathrm{F}$. There is a smooth variation in the velocity by a factor of about ro. This variation has the same period as the fluctuations of about $\pm 2 \mathrm{mK}$ in ambient temperature. Similar fluctuations were measured during experiment G.

Such variations do not arise from the effect of temperature on the measuring system. The variation of ambient temperature with time was small compared with the variation in temperature associated with the regelation process over the ice-water interface. Thus, we suggest that the system was able to adjust to the perturbation in temperature by smooth variations in both the velocity and the thickness of the water layer. For example, consider a small increase in the temperature of the cylinder. This leads to an increase in the number of heat sinks on the up-stream sides of the obstacles and a decrease in the number of sources on the down-stream sides. An increase in the regelation velocity requires an increase in the number of both sources and sinks. Melting on the down-stream side of the obstacles decreases the number of the sources. Thus the system could adjust to the small increase in ambient temperature by an increase in regelation velocity and a thickening of the water layer on the down-stream sides of the obstacles. Similarly, a small decrease in ambient temperature cou'd be countered by decreases in regelation velocity and the thickness of the water layer. In these experiments ambient temperature fluctuations of the order of $\pm \mathrm{I} 2 \mathrm{mK}$ would have led to complete freezing of the water layer during part of the cycle.

During experiments $\mathrm{E}$ and $\mathrm{F}$ temperature measurements were made between six pairs of thermoelectric junctions lying on the radius $r=27 \mathrm{~mm}$ half-way down the ice sample, and separated by $30^{\circ}$ or $90^{\circ}$. Figure 7 shows the variation of temperature difference with angular displacement of the cylinder. The temperature difference varies by \pm I I $\mathrm{mK}$ about a temporal mean of $17 \mathrm{mK}$. (The temporal mean should not be confused with the spatial mean temperature $T_{\mathrm{m}}$.) The other pairs of junctions gave similar variations but smaller mean temperature differences. For all pairs the maximum and minimum temperature differences occurred during experiment F. For each pair of junctions the mean temperature difference is subtracted from the recorded temperature differences and the average of the resulting set of temperature difference curves is shown in Figure 8.

Initially, each thermocouple junction was adjacent to either an edge or the mid-point of a cylinder face. Thus, from the simple theory, the expected regelation temperature distribution should lead to a variation in temperature difference which is an odd function of displacement, 


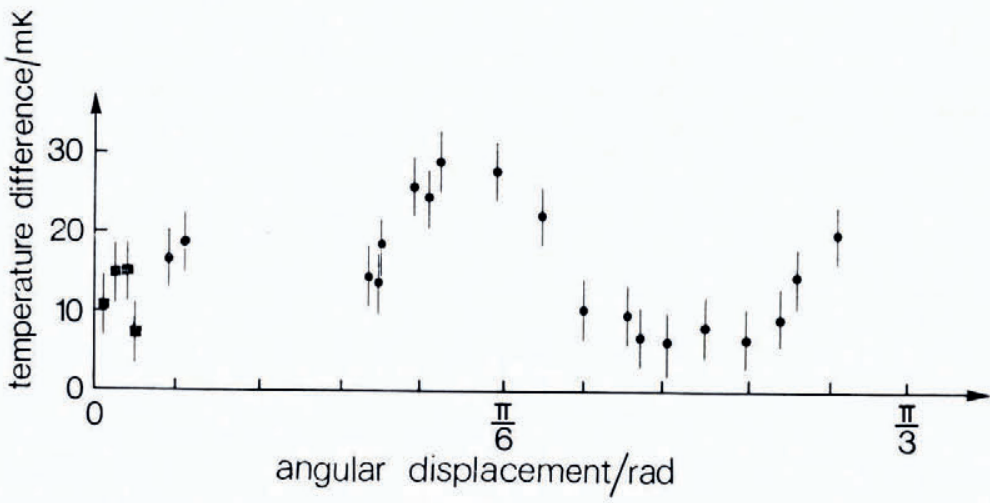

Fig. 7. The temperature difference between two points, on the radius $r=27 \mathrm{~mm}$ and separated by $30^{\circ}$, as a function of displacement of the hexagonal cylinder during the regelation stage (experiment $E$ results are shown by $\square$ and $F$ results by $\mathbf{O})$.

positive in the range $0^{\circ}<\theta<30^{\circ}$ and negative in the range $30^{\circ}<\theta<60^{\circ}$. The expected amplitude of this variation, for the average applied shear stress of $0.0388 \mathrm{MPa}$, is ro mK. The perturbation analysis which leads to this result is based on the assumption that to first order the regelation heat sources and sinks may be said to lie on $r=R_{N}$. In fact, they lie on the icewater interface and therefore second-order effects are expected to appear as a variation in temperature difference which is an even function, positive in the ranges $0^{\circ}<\theta<15^{\circ}$ and $45^{\circ}<\theta<60^{\circ}$. An even functional dependence would also be produced by a small, steady flow of extra heat to or from the cylinder as a result of inadequate temperature control. A steady temperature gradient across the ice block would produce a constant temperature difference.

The mean of the maximum and minimum measured temperature differences for a pair of junctions is a good estimate of the constant temperature difference between them during experiment $\mathrm{F}$ but is probably not a good estimate of the difference during experiment $\mathrm{E}$ since it is unlikely that the temperature gradients across the ice block would have been the same in

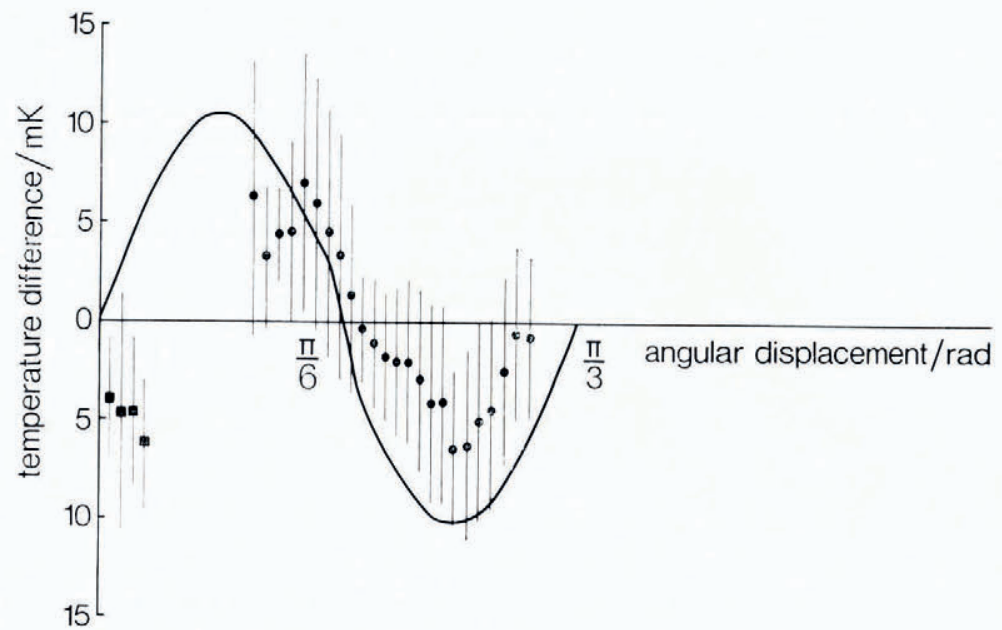
Fig. 8. The average temperature difference as a function of displacement of the hexagonal cylinder (experiments E, and F, - )
The solid line shows the theoretical curve. 
the two experiments. This is almost certainly the reason why our calculations give negative rather than positive average temperature differences in experiment $\mathrm{E}$ (Fig. 8).

Uncertainty in the estimation of the mean temperature differences also contributes to the large error bars on all the points. The expected curve, of amplitude $10 \mathrm{mK}$, is shown for comparison. On the basis of the simple theory a curve of amplitude $125 \mathrm{mK}$ would be expected to be associated with the measured regelation velocities.

The constant temperature differences of up to $17 \mathrm{mK}$ between pairs of junctions could arise from a steady temperature gradient across the ice block, not all parts of which would then be at the melting point. However, the geometry of the temperature distribution derived from the temperature differences in experiment $\mathrm{F}$ is complicated and difficult to reconcile with the possible directions of heat flow to and from the ice block. It is more likely that the whole of the ice block is at the melting point and that the temperature differences are caused by variations in the impurity concentration and grain structure in the immediate neighbourhood of each junction. In this case the temperature differences would distort the pattern of regelation heat-flow through the ice but the temperature distribution along the ice-water interface would not be affected. Since the heat flow through the ice is small compared with the flow through the brass the regelation process could proceed, as in experiments $\mathrm{E}$ and $\mathrm{F}$, apparently unaffected by the temperature differences.

Figures 9 and ro show photographs of thin sections cut from the samples. Each Figure has two photographs, (a) taken normally and (b) taken with the sample between crossed polarizing filters. The ice shown in Figure 9 has not undergone regelation but otherwise has the same history as the specimen shown in Figure ro. This latter specimen is part of the sample used in experiments $\mathrm{E}$ and F. A number of the features on all photographs appear during the preparation of the thin sections. The white bubbly ice at the bottom of Figure 9 and in the centre of Figure ro was added to the sample in order to protect its inner surface. A triangular chip in one face shown in Figure ro was also filled with bubbly ice.

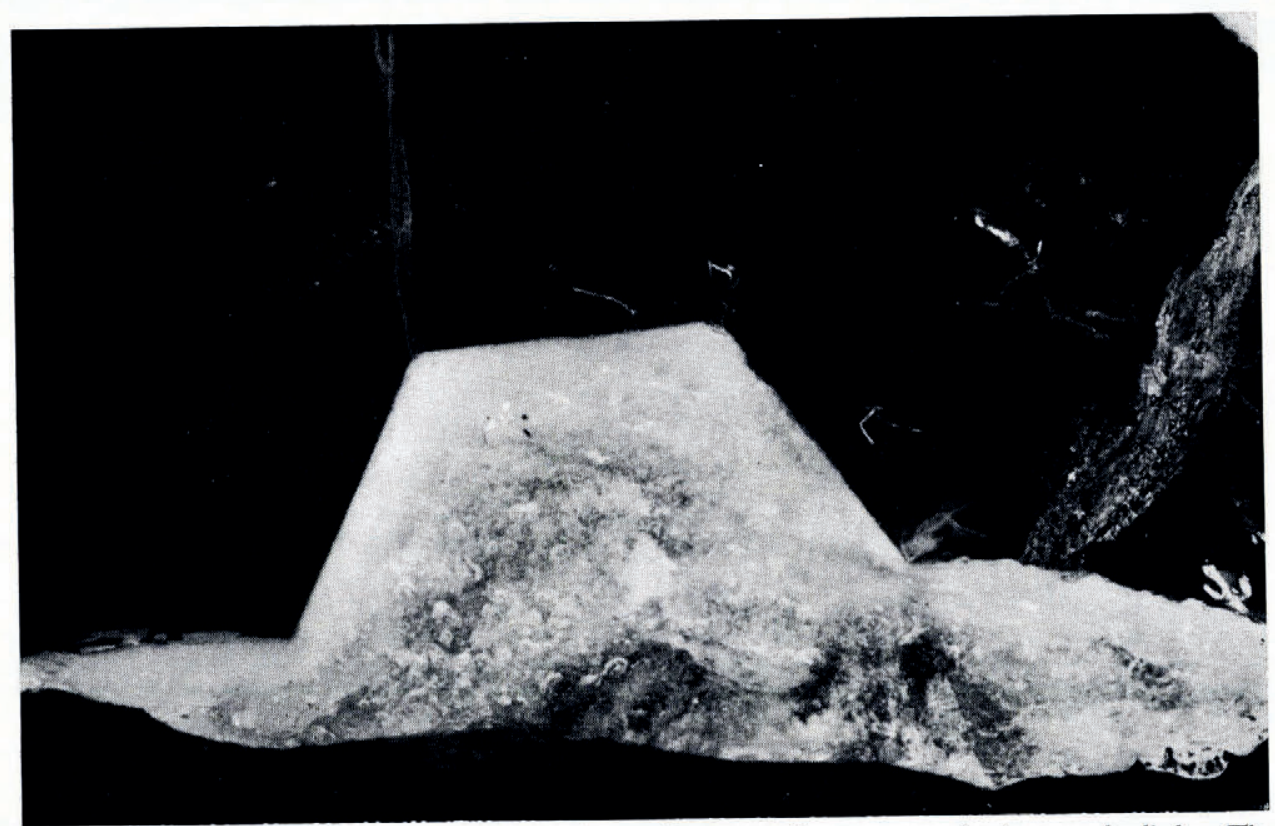

Fig. $9(a)$. An ice sample before regelation. A thin section cut from a sample grown around a hexagonal cylinder. The ice is lying on a black background. 
In Figure 9 the ice near the surface of the cylinder is clear except for two veils of air bubbles, one extending from an upper edge of the inner surface of the sample, the other at the right of the picture. These mark the position of cracks which were probably caused by a thermal shock experienced by the specimen during the preparation of the thin sections. A few air bubbles may also be seen lying on a circular arc about $10 \mathrm{~mm}$ away from the hexagonal inner surface. These bubbles were trapped between ice growing outwards from the cylinder and ice growing inwards during the formation of the samples; within this circle of bubbles the ice fabric consists of large, columnar grains. Granular features are more apparent in Figure 9 (b) where, for example, the coarse-grained ice of the sample can easily be distinguished from the fine-grained ice added to protect the surface. Fringes on this photograph mark the position of the grain boundaries. The ice that has grown outwards from the cylinder consists of large crystals separated by radial grain-boundaries. The interface with the ice that has grown inwards appears as a circular arc about io $\mathrm{mm}$ from the surface. The ends of the thermocouple wires may also be seen near the inner surface of the sample in both photographs of Figure 9. These wires are often associated with grain boundaries.

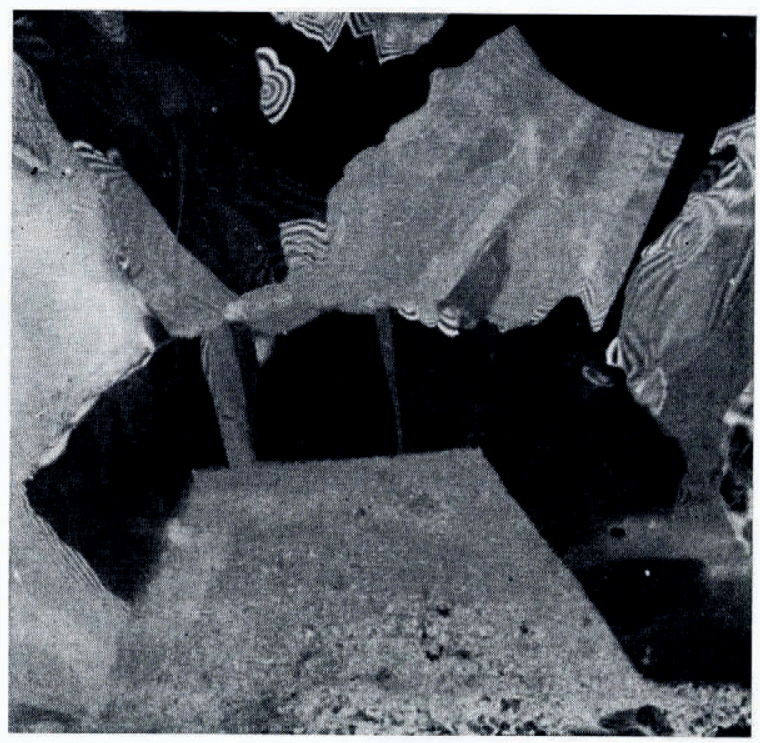

Fig. $g(b)$. The same section photographed between crossed polarizing filters.

In Figure ro two new features appear, a line of air bubbles very close to the inner surface (Fig. Io(a)) and a ring of fine-grained ice around it (Fig. Io(b)). The radial cracks in the sample were formed during the preparation of the section. The outer ring of bubbles was formed when the sample was grown whereas the inner ring of bubbles was formed during regelation. The boundary of the layer of fine-grained ice does not coincide with the inner bubble ring and at some points extends further into the ice than does the circumscribing radius of the hexagon (the fine-grained layer is clearest along the lower right-hand face of the inner surface of the sample). The mean distance from the point where the inner ring of bubbles cuts the surface to the nearest edge of the hexagon is $(0.1 \mathrm{I} \pm 0.07) \lambda$ for this section, and $(0.08 \pm 0.04) \lambda$ and $(0.07 \pm 0.07) \lambda$ for two other sections cut from the same sample. The boundary of the fine-grain area cuts the surface at $(0.4 \pm 0.04) \lambda$ from the nearest edge $((0.05 \pm 0.07) \lambda$ and $(0.08 \pm 0.06) \lambda$ in the other sections $)$ and does not coincide with the bubble line. 
Drake and Shreve report that during regelation the trace left by a brass wire consists of water and vapour bubbles in a layer which is thinner than the diameter of the wire and is centred on the lowest pressure point. In the viscometer experiment the impurities, including air, are expected to be shed in thin traces extending from the low- to the high-pressure points. The positions of these points are calculated, using the simple theory, to be $0.15^{\lambda}$ from the edges of the hexagon. The experimental data are consistent with this prediction but are not sufficiently precise to confirm it.

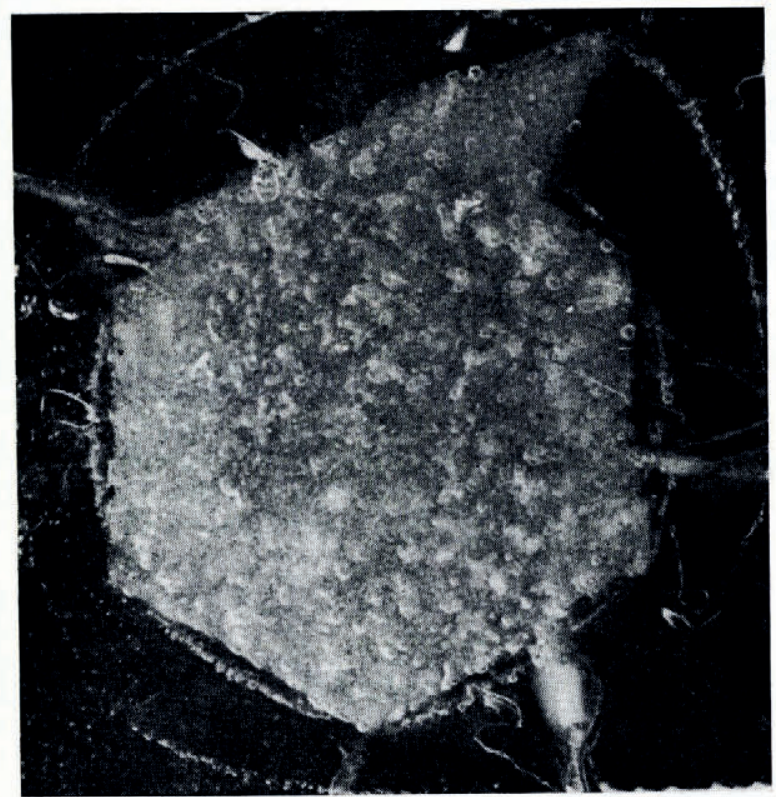

Fig. Io(a). An ice sample after regelation. A thin section cut from the sample used in experiments $E$ and $F$.

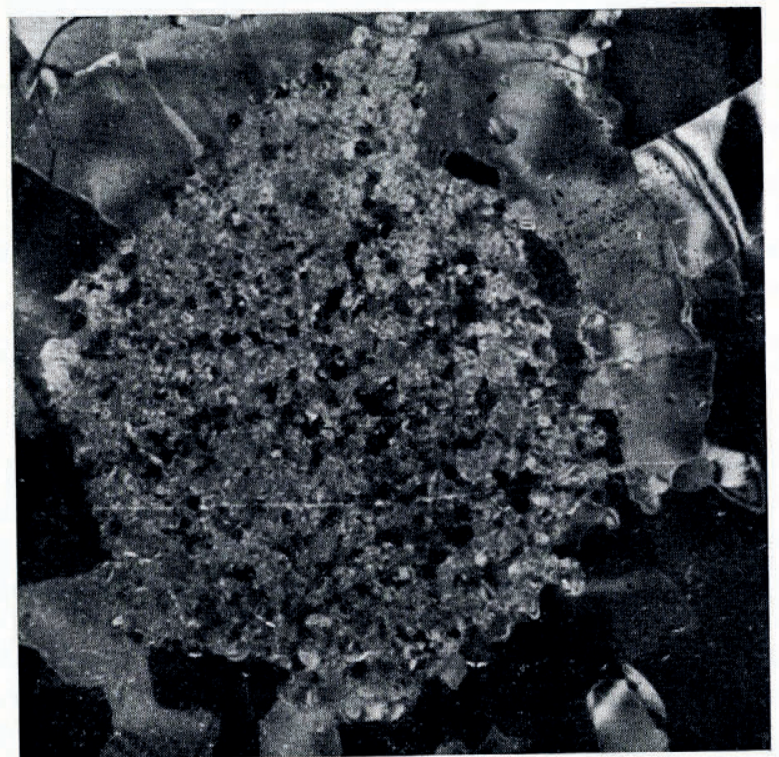

Fig. $10(b)$. The same section plotographed between crossed polarizing filters. 
The air bubbles of the trace are elongated in the regions near the edges of the hexagonal cylinder. The long axes of these bubbles lie in the plane of the section cut from the middle of the ice block. Near the upper surface of the block, however, the axes are inclined at a low angle to the horizontal plane, probably because the direction of growth of the bubble was affected by a small vertical temperature gradient. In the centre of the trace the bubbles are spherical.

\section{Conclusion}

The photographs of ice sections taken before and after regelation show that at least one impurity (air) has been shed into the ice during experiments $\mathrm{E}$ and $\mathrm{F}$. The line of bubbles close to the surface of the hexagon follows the path expected of a trace and has a form similar to that of the trace observed by Drake and Shreve (1973) for a brass wire. The liquid part of the trace has been frozen during preparation of the sections. In all the viscometer experiments the ratio between the expected and observed regelation velocities was $8 \pm 2$. We think that some experiments were carried out above the transition point (experiments A, B, C, D, E and $\mathrm{F}$ ) and some below this point (experiments $\mathrm{G}, \mathrm{H}$ and $\mathrm{K}$ ) but the ratio appeared to be independent of the transition point. We have suggested that, with the geometry used here, there need not be a change in the velocity ratio at the transition point. However, our results do not necessarily confirm this hypothesis since the average impurity concentration in the experiments was very small. Even if the impurity had been trapped in the water layer in experiments $\mathrm{G}, \mathrm{H}$ and $\mathrm{K}$, the increase in the ratio between the expected and observed regelation velocities would have been too small to have been detected. It is interesting that, despite the difference in geometry and scale, our results agree with those of Nunn and Rowell (1967) and Drake and Shreve (1973) for wires of brass or steel with similar thermal conductivities above the transition point.

There are several factors which may lead to a reduction in the regelation velocity above the transition point. Frank ( 1967$)$ has suggested that instability of the freezing surface might lead to separation of melt water from the down-stream side of an obstacle if the obstacle had a high thermal conductivity. When the water refroze the latent heat released would flow to the up-stream side of the obstacle by a path which might be longer and of lower conductivity than expected. In the viscometer experiments the maximum possible reduction in velocity, by a factor of about four, would occur if refreezing took place half-way between the edges of the cylinders.

We have calculated the expected regelation velocity using a linear flow-law for the ice. The accuracy of this calculation depends on how the strain-rate varies with the stress within the range of stresses used in the viscometer experiments. In fact, the spatial variation in normal pressure on the surface of the cylinders was about $\pm 15 \times 10^{5} \mathrm{~Pa}$. From Glen's law the difference between the maximum and mean "viscosities" was thus about $50 \%$. Although the viscosity does not appear explicitly in the pure regelation equations, differences between the measured and predicted velocities of the order of $50 \%$ are to be expected as a result of the non-linear flow-law of ice.

The presence of a trace (Drake and Shreve, I973) will not produce a significant reduction in the regelation velocity in the experiments reported here since the fraction of the volume swept out by the obstacles is very small. The change in pressure distribution around the cylinder as a result of the trace will be negligible. Loss of water from the regelation layer (Meerburg, 1907) could not have occurred by flow, either along the cylinder or into air bubbles, since the viscometer chamber was sealed and the ice near the cylinder was clear.

The effect of supercooling appears to be great enough to account for the eight-fold reduction in regelation velocity. Supercooling has already been suggested by Drake and Shreve to be a principal reason for the reduction in regelation velocity above the transition stress. As Nye ( 1967 ) has pointed out, if a certain amount of supercooling is required to freeze ice at a finite rate then the regelation temperature difference across an obstacle will be less than 
expected and there will be a corresponding reduction in regelation velocity. The magnitude of this effect will increase with increasing velocity. However, our results indicate that even when the regelation velocity is reduced by a factor of eight the corresponding temperature difference is not reduced by more than about $50 \%$. Thus, supercooling cannot be the major cause of the reduction in regelation velocity in the viscometer experiments.

Although Nye ( 1967$)$ states explicitly that his solution for the temperature distribution in the ice will not be quite accurate due to internal melting and refreezing, the presence of extra heat sources and sinks has not hitherto been considered to be a possible explanation for the unexpectedly low regelation velocities in traditional regelation experiments. However, if the temperature distribution due to internal melting and refreezing $T_{\mathbf{i}}(r, \theta)$ (Equation (9)) is not negligible the discrepancy between our measured regelation velocity and the temperature distribution could be explained. Measurements of temperature have not been made in any other regelation experiments so that at present it is not clear if the same discrepancy occurs in experiments with single objects.

\section{Acknowledgements}

These experiments were performed while I was a research student, supported by the Science Research Council, at the H. H. Wills Physics Laboratory, University of Bristol. The Natural Environment Research Council provided a grant for some of the equipment. I have been greatly helped by the advice of my supervisor, Professor J. F. Nye, and by many informal discussions with others interested in regelation, especially $\mathrm{Dr}$ J. W. Glen, Professor D. Tabor, Dr G. de Q. Robin, and Mr D. J. Goodman.

MS. received 26 September 1974 and in revised form I I June 1975

\section{REFERENCES}

Barnes, P. Unpublished. Plastic flow, pressure melting and other mechanisms in the deformation of ice Ih. [Ph.D. thesis, University of Cambridge, 1968.]

Drake, L. D., and Shreve, R. L. 1973. Pressure melting and regelation of ice by round wires. Proceedings of the Royal Society of London, Ser. A, Vol. $33^{2}$, No. ${ }^{5} 58$, p. $51-83$.

Frank, F. C. 1967. Regelation: a supplementary note. Philosophical Magazine, Eighth Ser., Vol. 16, No. 144,

p. 1267-74.
Lliboutry, L. A. 1971. Permeability, brine content and temperature of temperate ice. Fournal of Glaciology, Vol. 10, No. 58, p. $15^{-29}$.

Meerburg, J. H. I907. Over de beweging van een metaaldraad door een stuk ijs. Koninklijke Akademie van Wetenschappen te Amsterdam. Verslag van de Gewone Vergaderingen der Wis- en Natuurkundige Afdeeling, Deel 15, 2, p. $638-47$.

Meerburg, J. H. rgog. Over de beweging van een metaaldraad door een stuk ijs. II. Koninklijke Akademie van Wetenschappen te Amsterdam. Verslag van de Gewone Vergaderingen der Wis- en Natuurkundige Afdeeling, Deel 17, 2, p. 908-13.

Morrij, E. M. Unpublished. The sliding of ice over rock and other substances. [Ph.D. thesis, University of Bristol, 1972.]

Nunn, K. R., and Rowell, D. M. 1967. Regelation experiments with wires. Philosophical Magazine, Eighth Ser., Vol. 16 , No. 144 , p. $1281-83$.

Nye, J. F. 1967. Theory of regelation. Philosophical Magazine, Eighth Ser., Vol. 16, No. 144, p. 1249-66.

Nye, J. F. I 1969 . A calculation of the sliding of ice over a wavy surface using a Newtonian viscous approximation. Proceedings of the Royal Society of London, Ser. A, Vol. 31 i, No. 1506, p. 445-67.

Nye, J. F. 1970. Glacier sliding without cavitation in a linear viscous approximation. Proceedings of the Royal Society of London, Ser. A, Vol. 315, No. 1522, p. 381-403.

Nye, J. F. 1973. The motion of ice past obstacles. (In Whalley, E., and others, ed. Physics and chemistry of ice: papers presented at the Symposium on the Physics and Chemistry of Ice held in Ottawa, Canada, 14-18 August 1972. Edited by E. Whalley, S. F. Fones, L. W. Gold. Ottawa, Royal Society of Canada, p. 387-94.)

Ornstein, L. S. 19o6. Over de beweging van een metaaldraad door een stuk ijs. Koninlijke Akademie van Wetenschapper te Amsterdam. Verslag van de Gewone Vergaderingen der Wis-en Natuurkundige Afdeeling, Deel 1 4, 2, p. 629-35.

Rektorys, K. 1969. Survey of applicable mathematics. London, Iliffe Books Ltd.

Townsend, D. W., and Vickery, R. P. 1967. An experiment in regelation. Philosophical Magazine, Eighth Ser., Vol. 16, No. 144, p. 1275-8o.

Weertman, J. 1957. On the sliding of glaciers. Journal of Glaciology, Vol. 3, No. 21, p. 33-38.

Weertman, J. I964. The theory of glacier sliding. Journal of Glaciology, Vol. 5, No. 39, p. 287-303. 